\title{
Intensive Patient Treatment
}

\begin{abstract}
Intensive care units (ICUs) are treating hospital's poorest patients that need medical assistance during the most extreme period of their life. Intensive patients are treated with extensive invasive procedures, which may cause a risk of hospital infections in 10-30\% of the cases. More than half of these infections can be prevented. The patients are often admitted directly from outside the hospital or from abroad with trauma after accidents, serious heart and lung conditions, sepsis and other life-threatening diseases. Infection or carrier state of microbes is often unknown on arrival and poses a risk of transmission to other patients, personnel and the environment. Patients that are transferred between different healthcare levels and institutions with unknown infection may be a particular risk for other patients. In spite of the serious state of the patients, many ICUs have few resources and are overcrowded and understaffed, with a lack of competent personnel. ICU should have a large enough area and be designed, furnished and staffed for a good, safe and effective infection control. The following chapter is focused on practical measures to reduce the incidence of infections among ICU patients.
\end{abstract}

\section{Keywords}

Intensive patient $\cdot \mathrm{ICU} \cdot$ Nosocomial infections $\cdot$ Infection control $\cdot$ Hygiene Prevention

\subsection{Purpose}

Prevent nosocomial infection during intensive patient care. 


\subsection{Comprise}

All patients treated in intensive care units (ICUs) and personnel working in the intensive care units.

\subsection{Responsibility}

The hospital's management should provide resources and written guidelines regarding infection control work, proper patient/care ratio, sufficient patient areas, isolation capacity and documented competence.

The departmental management should provide competent personnel that follow guidelines. In circumstances that expose patients to increased infection risk, this is reported to the director immediately.

The staff follows routines. Expertise and practice in intensive medicine must be documented. It should be reported to the management if exposed to or infected by resistant or special microbes, for example, in work at other departments/countries.

The patient and relatives/visitors should be informed about the department's routines, hand hygiene and good personal hygiene and cleanliness.

\subsection{Practical Measures}

Intensive care unit (ICU) should have a large enough area and furnished for a good, safe and effective infection protection [1]. The state of infection or carrier state is often unknown on arrival and poses a risk of infection to other patients, personnel and the environment [2-15]. Patients transferred between healthcare levels and healthcare networks may spread infections [12-16].

Note! Comprehensive responsibility! There must be one responsible department/ unit manager who has total responsibility for patients, personnel and the environment - in terms of infection control and patient protection. Fragmentary leadership means that no one has direct responsibility for the patient's security and prevention of infection.

1. Hygienic standard should correspond to an operation department - to reduce the number of infections, the use of antibacterial agents and resistance development. Employees should carry out a good personal hygiene (see personal hygiene and regimes for isolation, Chap. 6 and 6-14).

2. Separate patient rooms are recommended. This is due to the many direct openings into sterile tissues, via respirator, intravascular catheters, urinary tract catheter, surgical site and other wounds. All intensive patients should be protected against infections from other patients, personnel and the environment [1, 17]. When sharing a room with a fellow patient, the distance between the patients must be $3-4 \mathrm{~m}$ from bed edge to bed side, and no one must have infections. 
3. Medical technical equipment associated with every intensive bed take a lot of space in the room, generates dust, particles and heat and are easily contaminated with skin particles and bacteria. Written cleaning procedures must be available for all equipment.

4. The burden of bacteria, particles and other organic materials from the use of respirators, cough/suctions and particles from opening single-use equipment needs good room ventilation, preferably more than ten air exchanges/hour and control of bacterial numbers in the air, $<100 \mathrm{CFU} / \mathrm{m}^{3}$. The air should enter the ceiling level and be filtered by $99 \%$ effective filter with particle diameter max $5 \mu \mathrm{m}$. Exhaust air is extracted approximately $15 \mathrm{~cm}$ above floor level (opposite side). Avoid turbulence, shaking of clothes, abrupt removal of bandages, etc. that increase the amount of bacteria in the air [7].

5. Hand hygiene is routinely enjoined for all personnel. Proper use of hand disinfectants and gloves is important. Non-sterile gloves often have a rich growth of environmental flora and do not protect the patient. Jewellery, piercing and wristwatches are not allowed since this collects microbes and inhibits personal hygiene/hand hygiene. Patient and visitor's hand hygiene routines will usually be the same in the hospital [18].

6. Coats and outerwear are taken off outside the unit.

7. Glove box for each patient, set date, and throw the box when the treatment ends.

8. Water control. Avoid splashes and aerosols from the sinks that are often colonized with gram-negative rods, and check the water for Legionella and other gram-negative bacteria (see Legionella and water control) [8, 9, 19].

(a) Cooling systems, water coolers and large water reservoirs are linked to the outbreak of Legionella and resistant gram-negative rod bacteria [20]. Use sterile water for intensive care patients for oral hygiene.

(b) Biofilm formation in water systems, on surfaces, etc. is increasing. Preventative measures are good such as daily cleaning with soap and water and disinfecting with chlorine or peracetic acid [19-21]. Biofilm can be resistant to chlorine [21].

9. Clean work uniform; change every day or more often if necessary.

(a) Separate gown for each patient—long arms and cuffs. The gown is changed for each shift or more frequently if contaminated.

(b) Cap/surgical mask and visor are used by work with respiratory tract (respirator), intravascular catheter, surgical wound, drain, urinary tract catheter.

10. Cleanliness and order to reduce biological burden in the environment and to reduce the risk to the patient. Good daily cleaning removes possible pathogenic flora fairly quickly. Good cleaning depends on good space and order. Large amounts of skin waste, hair and microbes are released continuously from people in the room - and fall down as grey "dust" on all surfaces after the floating state in the air-and carry invisible amounts of bacteria. In addition, there may be huge amounts of particle release from all disposable devices that are opened.

(a) All patient rooms, service rooms, guard rooms, wardrobes, etc. must be cleaned at least once a day with soap and water.

(b) The washbasin is washed and disinfected daily [19]. 
(c) All horizontal surfaces in patient rooms are washed daily.

(d) In order to carry out proper cleaning on surfaces, shelves and cabinets, only necessary equipment, clothes, etc. should be present.

(e) All cabinets in the patient room/intensive room are cleaned weekly.

(f) There should be no stockholding in patient rooms, except for what is needed for today's use.

(g) Toilets are cleaned $\times 2$. See cleaning chapter.

(h) After use to a patient, everything in the closet must be discarded, and the cabinet should be thoroughly washed.

(i) Cabinets and shelves in service rooms must be cleaned once a month.

(j) All equipment must be cleaned after each use and before it is stored.

(k) PCs, telephones, data in the patient room and the like should be washed over after each shift; if necessary put on a new plastic bag for each shift.

(1) Main cleaning two times a year.

Disinfect mobile phones, glasses, etc. and all other equipment before being brought into the ICU.

Note! Persons who perform room cleaning should not work with patients at the same time. This is to avoid cross infection.

11. Medical technical equipment must be cleaned outside daily, when the treatment is completed and when it is going to enter or leave the department. It must also be cleaned inside after infection and after certain periods of use or after each use. All equipment is stored clean and dry, preferably with a clean chapel, on a separate clean storage.

12. Sterile equipment is stored clean and dry on a separate storage for sterile equipment with requirements of low bacterial numbers in the air.

13. Respiratory treatment: see separate chapters.

14. Intravascular treatment: see separate chapters [22-26].

15. Urinary tract infection preventive treatment: see separate chapter.

16. All drains, catheters, surgical wounds, other wounds, etc. should be treated sterile with closed drainage (if use of drainage); see separate chapters.

17. Isolates: the ICU must have sufficient number of good isolates for contact- and airborne infections. See isolation regimes Chaps. 14-21.

18. Isolation is performed if uncontrolled wound secretion (pus), or suspected contactor air transmission; MRSA, VRE, GAS (Group A streptococci), meningococci, ESBL, EHEC, Pseudomonas, Acinetobacter, Serratia and other resistant bacteria, TBC, Clostridium difficile, gastrointestinal pathogenic bacteria and viruses (norovirus etc.) and airway pathogenic bacteria or - viruses (influenza virus, etc.); see isolation regimes.

19. Define contaminated waste, and review procedures for removing such waste.

20. Disinfection room with decontaminator and instrument washing machine is checked weekly.

21. Patients should be on a single room $\left(25 \mathrm{~m}^{2}\right.$ per bed $) /$ isolated from each other, for example, using "glass cages" (see point 2). 


\subsubsection{Need for Personnel:Patient/Nurse Ratio, 1:2}

There is estimated at least two competent intensive care nurses per patient. The ICU patient is monitored continuously — in place — at the bed (not via ward room) on a 24-h basis. Small changes in the patient can lead to a dramatic worsening of the condition if not detected early enough.

Understaffing leads to less competent personnel and temporary workers, increased stress in the work situation, reduced hand hygiene and lack of infection control [5]. This increases the risk of serious nosocomial infection and fatal outcome. Understaffing and overcrowding will also expose personnel and visitors to increased risk of infection [5].

\subsection{Background Information}

The ICU should be large enough to cover demographic needs, operational activity and specialty in the coverage area $[1,10,11]$. The department should be functional with ample space for each patient, necessary number of isolates, good ventilation, service rooms and storage space. The department must be prepared for good infection control, hand hygiene and a thorough cleaning system [1, 10, 11].

\subsubsection{Nosocomial Infections at Intensive}

Patient groups vary according to type of intensive care unit: surgically intensive, medical intensive, child intensive or a blend of patient categories.

- In Germany, nosocomial infections were detected in $9.4 \%$ of 1860 ICU patients, and after discharge, the rate increased to $10.6 \%$ [27]. Without follow-up afterwards, $12 \%$ of ICU-associated infections were not recorded [27].

- In Belgium, there were 6500 ICU patients examined in 2010 [28]. Nosocomial pneumonia and ventilator-associated pneumonia (VAP) starting in the ICU were $13 / 1000$ and 12/1000 patient days, respectively, and ICU-associated blood infections were 3.2/1000 patient days. During the period 1997-2010, ICU-associated infections increased, while infections related to equipment (respirator, catheter) were reduced [28]. In 2010, at least $31 \%$ of adult ICU patients had nosocomial infections [29].

- Later studies showed that more than $10 \%$ of ICU patients had infections like VAP and catheter-associated infections [30]. Among 78, 200 patients with more than 2 days of stay in 525 ICUs in 6 European countries from 2005 to 2008, it was estimated that $52 \%$ of the VAP cases and $69 \%$ of bloodstream infections could be prevented [30].

- Intensive studies in the United States show that $65-70 \%$ of catheter-associated blood and urinary tract infections can be prevented and $55 \%$ of cases of VAP and postoperative wound infections [31]. 
- The American network study (2013) of catheter-associated intravascular and urinary tract infections, VAP and postoperative wound infections showed that these four infection categories caused 70,000 hospital infections per year, and it was found at least 81,000 pathogenic microbes in these patients [32]. Nearly $20 \%$ of the microbes were multidrug-resistant organisms (MDRO) like MRSA, VRE, ESBL and CRE isolates [32].

\subsubsection{Intensive Beds and Nosocomial Infections in Norway}

- In 2010, ca. 300 general intensive beds were registered at 44 hospital ICUs in Norway (five million inhabitants) [33]. In 2013 it was about 15, 200 ICU treatments and approximately 60,300 days of intensive care in Norway are distributed between local hospitals $28.6 \%$; central hospitals, $34.5 \%$; and regional hospitals, $36.9 \%$ [34].

- More than half of the patients were on respiratory treatment, average stay in the ICU was 4 days, and $82.8 \%$ were discharged from hospital, while $11 \%$ died on the ICU and $6.2 \%$ on other wards [34].

- There is a calculated need for about 11 ICU beds per 100,000 inhabitants [35]. Calculated from today's approximately 350 intensive beds, this amounts to $5.8 / 100,000$.

- In 2015, the prevalence of hospital infections in the Norwegian ICUs was $23 \%$ in surgical ICU/postoperative ward (218 beds) and $11.5 \%$ in medical ICU/ward of monitoring (192 beds) [36]. About the same results were recorded in 2013 [36].

- Hospital infections and mortality are high in Norwegian ICUs, especially in surgical ICUs. Since postoperative beds are included in the number registered for intensive, the real number of hospital infections is probably much higher. The costs are uncertain but probably amounts to at least $36,000 \mathrm{NKr}$ per day for regular intensive care. The presence of resistant microbes in Norwegian ICUs is unknown but probably an increasing problem.

- There are still too few ICU beds in Norway-maybe only half of what is needed - and this can lead to unnecessary disease and death [35]. Every 6th (17\%) ICU patient died on intensive or afterwards on ward in 2013 [34]. The risk of death in ICU is therefore very high.

\subsubsection{General Risk Factors for Infection in ICU}

- Many entry ports through skin/mucous membranes (trauma, surgical procedure, respirator, etc.).

- Flat bed rest over time.

- Reduced immunity to infections, impaired general condition.

- Many procedures and a lot of handling of the patient.

- Much instrumentation.

- Acute care procedures. 
- H-2 blockers with gastric colonization of gram-negative bacteria from the gut.

- Aspiration of stomach contents.

- Short distance between patients-high patient density and overcrowded.

- Many patients in the same room, open care-"dormitory" [2, 3, 17].

- Mixing of potentially infected patients with non-infected patients.

- Lack of isolates/single rooms and cross infection [1-3,37].

- Poor cleaning, lack of hygiene measures and lack of follow-up of hygiene guidelines $[6,38]$.

- Environmental contamination $[4,6]$.

- Contaminated water $[8,9]$.

- Biofilm formation with microbe growth in water, on surfaces and equipment $[20,21]$.

- Contaminated textiles.

- Contaminated/unsterile equipment and liquids [38].

- Contaminated patient room [39].

- Large consumption of antibacterial agents.

- The use of multi-dose vials instead of single-dose.

- Large nursing load on few nurses, patient/nurse ratio—understaffing [5].

- Short-term employed and a high personnel turnover [5].

- Lack of knowledge, experience and use of written routines, large number of part-time workers and many "leaders" in the system.

- Number of days in hospital $>7$ days; transferral of the patient between several departments and undergone at least one invasive procedure.

- Transport between departments and hospitals [15].

\subsubsection{Special Risk Factors/Procedures}

- Airborne-droplet-borne infection:

- Bacteria like S. aureus (including MRSA), tuberculosis, gram-negative bacteria, pneumococci, meningococci, etc.

- Respiratory virus like influenza, RSV, metapneumovirus, parainfluenza virus, bocavirus, etc.

- Exanthema virus like varicella, mumps, morbilli, rubella, enterovirus, parvovirus, etc.

- Diarrhoea virus—-special highly transmissible like noro-, sapo-, boca- and coronavirus, etc.

- Mechanical ventilation [40-42]. See separate chapter.

- Aerosol from contaminated nebulizer and other respiratory equipment.

- Aerosol/re-aerosol from change of bed linen, making the bed and other activities [7].

- Tracheal suction/coughing.

- Oral hygiene-lack of [43].

- Intravascular treatment, haemodialysis, peritoneal dialysis, etc. [22-26, 44].

- Drainages and urinary tract catheters. 
- Prolonged use of antibiotics and increasing bacterial resistance [42, 45].

- Personnel with infection/carrier state—without knowing — "cloud" personnel [46].

- Lack of tuberculosis control.

The greatest risk of infection is the number of days in the ICU and respiratory treatment (see separate chapter concerning VAP). The ICU patients have often complicating infections that lead to increased use of broad-spectrum antibacterial agents, which in turn often lead to resistant microbes. The patients' microbes become environmental, robust microbes that may be transmitted to the lungs, blood or wounds of room-mates. The accumulation of robust environmental microbes and bacterial-bearing dust (gram-negative rods, staphylococci and fungi), over time, is a great risk that may be removed only by good daily cleaning and environmental control.

\subsubsection{Important Microbes in the ICU}

Occasionally, patients bring serious infections or infectious agents to the hospital and the ICU; multi-drug resistant organisms (MDRO) such as MRSA, VRE, ESBL, EHEC (entero-haemorrhagic E. coli, may be ESBL at the same time), CRE (carbapenemase-producing/resistant Enterobacteriaceae). A number of others are introduced periodically in the department like norovirus and influenzae.

The most common infections in ICUs are caused by S. aureus, E. coli, Enterobacter, Pseudomonas, Klebsiella, Serratia, Acinetobacter, Stenotrophomonas, Burkholderia cepacia, Enterococcus, Clostridium difficile, coagulase-negative staphylococci and Candida. During the stay in the ICU, the early infections are often with "common" bacteria like staphylococci, and the later infections after longer stay in the ICU are caused by more resistant bacteria like Pseudomonas and fungi. In Sweden, an increased incidence of invasive Haemophilus influenzae, nontype $\mathrm{b}$, has been reported, with more than one third being treated at the ICU for septic shock [47].

Group A streptococci (GAS) are epidemic in a number of countries and constitute an important intensive treatment and infection problem. In England, there was registered 14,000 GAS cases in 2014-the highest number of the past 50 years of scarlet fever [48]. Healthcare professionals can become carriers of GAS, and the infection can spread through air $[46,49,50]$.

\subsubsection{Most Microbes May Become Airborne}

Bacteria that are transmitted via direct inhalation, swirling of dust or aerosols are GAS, staphylococci, MRSA, meningococci, pneumococci, pertussis bacteria, diphtheria bacteria, EHEC, Acinetobacter Legionella, Pseudomonas, Clostridium difficile (spores), Mycobacterium tuberculosis and other mycobacteria, Nocardia and a variety of other bacteria [46, 49-53]. 
Virus that is nosocomial through the air is respiratory virus (RSV, influenza, parainfluenza, rhinovirus, corona-, adeno-, entero-, parecho-, metapneumovirus), varicella-zoster virus, rubella, morbilli, norovirus, sapovirus, etc. [51]. Spores of fungi from Aspergillus and similar fungus types are liberated easily into the air and causes severe systemic infections in immunosuppressed patients [51].

\subsubsection{Antibiotics and Resistance in ICU}

Antibiotic resistance has increased dramatically over the past 20 years, and a large proportion of these occur in ICU departments with severe infectious disease [54-58].

New types of resistance appear as CRE (carbapenem resistant), Enterobacteriaceae: XDR (extensive drug resistance), Acinetobacter species; and totally resistant (NDM-1 and colistin resistant) gram-negative rods, extremely to totally resistant tuberculosis bacteria, and others that can cause fatal nosocomial progress, also in almost immune-competent patients [59-62]. These patients are often associated with ICU, respiratory treatment, pulmonary disease, antibiotic use and a high bacterial burden in the environment [59].

A specific "clad B" (XDR) strain of A. baumannii is-in the United States-a recent cause of fatal outcome of nosocomial infection in six patients: it is a highly resistant and dangerous (hypervirulent) strain [61]. Another multiresistant A. baumannii caused nosocomial infections in more than 19 patients, of which five died in Germany [62].

In a study from Brazil, the consumption of piperacillin-tazobactam, fluoroquinolones and cephalosporins increased at the hospital [63]. At the ICU, multi-resistance was detected in more than $30 \%$ of the cases, with increasing meropenem-resistant Klebsiella and Acinetobacter species. A significant correlation was detected between the proportion of multiresistant bacteria and the consumption of cephalosporins and fluoroquinolones [63].

Among 400 hospitalized patients in Germany, 18.5\% were colonized with fluoroquinolone-resistant E. coli (FQREC), and this was linked to poor clinical outcomes and high mortality [56]. Stay in hospital, cancer diagnosis and the use of first-generation cephalosporin or cefepime treatment increased the incidence of new colonization with FQREC [56]. Isolation, good hygienic measures and a better antibiotic policy reduce the spread of infection. Fluoroquinolone resistance is an increasing problem since these drugs are used extensively both inside and outside hospitals [55].

Multiresistant bacteria may increase when using antibiotics in food and beverage production. An alarming occurrence of carbapenemase-producing gram-negative bacteria has been detected in food, for example, in Canada [57]. Also in Norway there are significant problems with resistant bacteria and other unfortunate agents in some food products [64].

Resistant microbes in the health system will migrate between health levels, such as either silent colonization or with infection symptoms, "the top of the iceberg". 
The real problem (the entire iceberg) is only detected by general screening and mapping of the patients [12-15]. International studies show insufficient knowledge about how to use the testing of resistance against antibiotics, also shown in a Norwegian study [65, 66]. Today, active screening of faeces/rectum samples (CRE, ESBL, VRE, (MRSA)) may be used in combination with $C$. difficile detection [67]. This has proven cost effective in ICU departments with problems with A. baumannii [68].

Chlorhexidine "bathing" of ICU patients to reduce infections is discussed, both for adults and children [69]. This measure is probably not so successful concerning the development of resistance as long as it is done so little for general hygiene and infection control in ICUs.

In Norway, there is increasing resistance development and outbreaks of resistant microbes such as MRSA, VRE and ESBL in hospitals, especially in recent years, but is still thought to be a "limited problem" [70].

\subsubsection{Location, Area and Physical Environment at the ICU}

Many ICUs around the world, including Norway, have until recently appeared like large dormitories, with mix of patient categories, no isolates and a strong understaffing in old and run-down areas. The outmost sever ill patients have often had the poorest treatment offer in the ICU of the hospitals. "Bad design, bad practices, bad bugs" is the starting point for a number of serious infection outbreaks in ICUs [71].

- Space around the patient is needed for different intensive equipment, nursing staff and family. Each patient should have a separate room (approximately $25 \mathrm{~m}^{2}$ patient) to be protected against infection/noise/stress from the environment and other patients. Recent studies indicate that patients in separate ICU rooms will have fewer hospital infections and thus a lower risk of fatal outcome [72, 73].

- Isolates. Twenty-five percent of the bed capacity at intensive should be isolates with negative air pressure (16-25 Pa). The size should be at least $35 \mathrm{~m}^{2} /$ isolate which includes patient room, sluice and disinfection room/toilet/shower.

- Service room. The unit must have service rooms/store rooms adapted to the number of intensive beds. The service rooms should be store room for single-use equipment $\left(16 \mathrm{~m}^{2}\right)$, medicine room $\left(16 \mathrm{~m}^{2}\right)$, disinfection room (needed, crosscontamination danger, $16 \mathrm{~m}^{2}$ ), textile room (needed, danger of cross-contamination, $16 \mathrm{~m}^{2}$ ) for technical equipment (respirator, infusion pumps, surveillance equipment, racks, etc., 15-20 $\left.\mathrm{m}^{2}\right)$, shower room for patients $\left(4 \mathrm{~m}^{2}\right)$ and waste disposal room (large amounts of waste, $12 \mathrm{~m}^{2}$ ).

- Entrance control. A separate sluice for entrance to the ICU with wardrobes with washbasins and disinfectants.

Note: Washbasins/sinks/shower rooms. A number of studies have documented bacterial aerosols around the sink/washbasin/shower room. A French multicentre study of 185 washbasins in 13 ICUs showed that one of three washbasins was contaminated with multiresistant ESBL gram-negative bacteria [19]. It was 
recommended that washbasins should only be used for hand washing and disinfected with chlorine agents daily [19]. Washbasins, with a small fall height from opening to bottom, should therefore be placed at least $2 \mathrm{~m}$ from the patient to avoid aerosols.

\section{References}

1. O'Connell NH, Humpreys $\mathrm{H}$. Intensive care unit design and environmental factors in the acquisition of infection. J Hosp Infect. 2000;45:255-62.

2. Weist K, Pollege K, Schulz I, Ruden H, Gastmeier P. How many nosocomial infections are associated with cross-transmission? A prospective cohort study in a surgical intensive care unit. Infect Control Hosp Epidemiol. 2002;23:127-32.

3. D'Agata EMC, Thayer V, Schaffner W. An outbreak of Acinetobacter baumannii: the importance of cross-transmission. Infect Control Hosp Epidemiol. 2000;21:588-91.

4. Olafsen K, Hotvedt R, Andersen BM, Almdahl SM, Sørlie D. Nosokomial infection with resistant Enterobacter cloacae. Tidsskr Nor Legeforen. 1989;109:332-6.

5. Andersen BM, Lindemann R, Bergh K, Nesheim BI, Syversen G, Solheim N, Laugerud F. Spread of methicillin-resistant Staphylococcus aureus in a neonatal intensive unit associated with understaffing, overcrowding and mixing of patients. J Hosp Infect. 2002;1:1-7.

6. Levin AS, Gobara S, Mendes C, Cursino R, Sinto S. Environmental contamination by multidrug-resistant Acinetobacter baumannii in an intensive care unit. Infect Control Hosp Epidemiol. 2001;22:717-20.

7. Shiomori T, Miyamoto H, Makishima K, Yoshida M, Fujiyoshi T, Udaka T, et al. Evaluation of bed-related airborne and surface methicillin-resistant Staphylococcus aureus contamination. J Hosp Infect. 2002;50:30-5.

8. Trautmann M, Michalsky T, Wiedeck H, Radosavljevic V, Ruhnke M. Tap water colonization with Pseudomonas aeruginosa in a surgical intensive care unit (ICU) and relation to pseudomonas infections of ICU patients. Infect Control Hosp Epidemiol. 2001;22:49-52.

9. Bukholm G, Tannæs T, Kjelsberg ABB, Smith-Erichsen N. An outbreak of multidrug-resistant Pseudomonas aeruginosa associated with increased risk of patient death in an intensive care unit. Infect Control Hosp Epidemiol. 2002;23:441-6.

10. Andersen BM, Moen H, Gjetrang H. Intensive patient treatment. In: Handbook for hygiene and infection control for hospitals. Oslo: Ullevål University Hospital; 2003. p. 305-9.

11. Andersen BM, Olafsen K. Prevention of infections in intensive patient care. In: Handbook for hygiene and infection control for hospitals. Oslo: Ullevål University Hospital; 2008. p. 400-4.

12. Munoz-Price LS. Carbapenem-resistant Enterobacteriaceae, long-term acute care hospitals, and our distortions of reality. Infect Control Hosp Epidemiol. 2013;34:829-33.

13. Lewis JC, Bishop M, Heon B, et al. Admission surveillance for carbapenemase-producing Enterobacteriaceae at a long-term acute care hospital. Infect Control Hosp Epidemiol. 2013;34:832-4.

14. Willemsen I, Nelson J, Hendriks Y, et al. Extensive dissemination of extended sprectrum beta-lactamase-producing Enterobacteriaceae in a Dutch nursing home. Infect Control Hosp Epidemiol. 2015;36(4):394-400.

15. Eveillard M, Quenon JL, Rufat P, Mangeol A, Fauvelle F. Association between hospitalacquired infections and patient transfers. Infect Control Hosp Epidemiol. 2001;22:693-6.

16. Nekkab N, Astagneau P, Temime L, Crepey P. Spread of hospital-acquired infections: a comparison of healthcare networks. PLoS Comput Biol. 2017;13(8):e1005666.

17. Daneman N, Scales DC, Lawless B, Muscedere J, Blount V, Fowler RA. Infection prevention and control in the intensive care unit: open versus closed models of care. Infect Control Hosp Epidemiol. 2013;34:867-71.

18. Barker A, Sethi A, Shulkin E, et al. Patient's hand hygiene at home predicts their hygiene practices in hospital. Infect Control Hosp Epidemiol. 2014;35:585-8. 
19. Roux D, Aubier B, Cochard H, et al. Contaminated sinks in intensive care units: an underestimated source of extended-spectrum beta-lactamase-producing Enterobacteriaceae in the patient environments. J Hosp Infect. 2013;85:106-11.

20. Guyot A, Turton JF, Garner D. Outbreak of Stenotrophomonas maltophilia on an intensive care unit. J Hosp Infect. 2013;85:303-7.

21. Hu H, Johani J, Gosbell IB, et al. Intensive care unit environmental surfaces are contaminated by multidrug resistant bacteria in biofilms: combined results of conventional culture, pyrosequencing, scanning electron microscopy, and confocal laser microscopy. J Hosp Infect. 2015;91:35-44.

22. Trarore O, Liotier J, Souweine B. Prospective study of arterial and central venous catheter colonization and arterial and central venous catheter-related bacteremia in intensive care units. Crit Care Med. 2005;33:1276-80.

23. Beekman SE, Henderson DK. Infections caused by percutaneous intravascular devices. In: Mandell, Douglas, Bennests, editors. Principles and practice of infectious diseases. 7th ed. London: Elsevier Churchill Livingstone; 2010. p. 3697-715. and 2015. p. 3310-24.

24. O'Grady NP, Alexander M, Burns LA, et al. Guidelines for the prevention of intravascular catheter-related infections, 2011. CDC. 2011.

25. Koh DBC, Gowardman JR, Rickard CM, et al. Prospective study of peripheral arterial catheter infection and comparison with concurrently centralized central venous catheters. Crit Care Med. 2008;36:397-402.

26. Hammarskjøld F, Wallen G, Malmvall BE. Central venous catheter infections at a county hospital in Sweden: a prospective analysis of colonization, incidence of infection and risk factors. Acta Anaesthesiol Scand. 2006;50:451-60.

27. Geffers C, Gastmeier P, Brauer H, Daschner F, Ruden H. Surveillance of nosocomial infections in ICUs: is postdischarge surveillance indispensable? Infect Control Hosp Epidemiol. 2001;22:157-9.

28. Mertens K, Morales I, Catry B. Infections acquired in intensive care units: results of national surveillance in Belgium, 1997-2010. J Hosp Infect. 2013;84:120-5.

29. Gordes B, Vrijens F, Hulstaert F, Deverse S, Van de Sande S. The 2007 Belgian National Prevalence Survey for hospital-acquired infections. J Hosp Infect. 2010;75:163-7.

30. Lambert ML, Silversmit G, Savey A, et al. Preventional proportion of severe infections acquired in intensive care units. Case-mix adjusted estimations from patient-based surveillance data. Infect Control Hosp Epidemiol. 2014;35:494-501.

31. Umscheid CA, Mitchell MD, Doshi JA, et al. Estimating the proportion of healthcare-associated infections that are reasonably preventable and the related mortality and costs. Infect Control Hosp Epidemiol. 2011;32:101-14.

32. Sievert DM, Ricks P, Edwards JR, et al. Antimicrobial-resistant pathogens associated with healthcare-associated infections: summary of data reported to the National Healthcare Safety Network at the Centers of Disease Control and Prevention, 2009-2010. Infect Control Hosp Epidemiol. 2013;34:1-14.

33. Flaatten H, Søreide E. Intensive medicine in Norway. Tidsskr Nor Legeforen. 2010;130:166-8.

34. NorskIntensivregister. Annual report for 2013. Kvåle R. Haukeland University Hospital.

35. Project 'Intensive Capacity'. Follow-up of pre-project for health care organization structure and task allocation in Helse Øst. Norway.

36. NIPH. Prevalence of health-related infections in hospitals 2013, 2014, 2015. FHI, Oslo, Norway.

37. Van Dort M, Walden C, Walker ES, Reynolds SA, Levy F, Sarubbi FA. An outbreak of infections caused by non-typable Haemophilus influenzae in an extended care facility. J Hosp Infect. 2007;66:59-64.

38. Gravel D, Sample ML, Ramotar K, Toye B, Oxley C, Garber G. Outbreak of Burkholderia cepacia in the adult intensive care unit traced to contaminated indigo-carmine dye. Infect Control Hosp Epidemiol. 2002;23:103-6.

39. Nseir S, Blazejewski C, Lubret R, et al. Risk of acquiring multidrug-resistant Gram-negative bacilli from previous room occupants in the ICU. Clin Microbiol Infect. 2010;17:1201-8. 
40. Lai KK, Baker SP, Fontecchio SA. Impact of a travelling of intensive surveillance and intervention targeting ventilated patients in the reduction of ventilator-associated pneumonia and its cost-effectiveness. Infect Control Hosp Epidemiol. 2003;24:859-63.

41. Babcock HM, Zack JE, Garrison T, Trovillion E, Kollef MH, Fraser VJ. Ventilator-associated pneumonia in a multi-hospital system: differences in microbiology by location. Infect Control Hosp Epidemiol. 2003;24:853-8.

42. Fagon JY, Rello J. Targeted antibiotic management of ventilator-associated pneumonia. Clin Microbiol Infect. 2006;12:17-22.

43. Chan EY, Ruest O, Meade M, Cook DJ. Oral decontamination for prevention of pneumonia in mechanically ventilated adults: systematic review and meta-analysis. Br Med J. 2007;334:889-93.

44. Mimoz O, Villeminey S, Ragot S, et al. Chlorhexidine-based antiseptic solutions versus alcoholbased povidone-iodine for central venous catheter care. Arch Intern Med. 2007;167:2066-72.

45. Tenover FC, Biddle JW, Lancaster MV. Increasing resistance to vancomycin and other glycopeptides in Staphylococcus aureus. Emerg Infect Dis. 2001;7:327-32.

46. Sherertz RJ, Bassetti S, Bassetti-Wyss B. "Cloud" health-care workers. Emerg Infect Dis. 2001;7:241-4.

47. Resman F, Ristovski M, Ahl J, et al. Invasive disease caused by Haemophilus influenzae in Sweden 1997-2009; evidence of increasing incidence and clinical burden of non-type b strains. Clin Microbiol Infect. 2011;17:1638-45.

48. Promed-mail on 14 Mar 2015. Streptococcus group A, scarlet fever - UK: England, update.

49. Kolmos HJ, Svendsen RN, Nielsen SV. The surgical team as a source of postoperative wound infection caused by Streptococcus pyogenes. J Hosp Infect. 1997;35:207-14.

50. Talbot TR, May AK, Obremsky WT, Wright PW, Daniels TL. Intraoperative patient-to-healthcare-worker transmission of invasive group A streptococcal infection. Infect Control Hosp Epidemiol. 2011;32:924-6.

51. Schaal KP. Medical and microbiological problems arising from airborne infection in hospitals. J Hosp Infect. 1991;18. (Suppl A:451-9.

52. Gehanno JF, Louvel A, Nouvellon M, et al. Aerial dispersal of methicillin-resistant Staphylococcus aureus in hospital rooms by infected and colonised patients. J Hosp Infect. 2009;71:256-62.

53. Wong BCK, Lee N, Li Y, et al. Possible role of aerosol transmission in a hospital outbreak of influenza. Clin Infect Dis. 2010;51:1176-83.

54. Cassier P, Lallechere S, Aho S, et al. Cephalosporin and fluoroquinolone combinations are highly associated with CTX-M beta-lactamase-producing Escherichia coli : a case-control study in a French teaching hospital. Clin Microbiol Infect. 2011;17:1764-51.

55. Dalhoff A. Resistance surveillance studies: a multifaceted problem - the fluoroquinolone example. Infection. 2012;40:239-62.

56. Han JH, Bilker WB, Nachamkin I, et al. Impact of antibiotic use during hospitalization on the development of gastrointestinal colonization with Escherichia coli with reduced fluoroquinolone susceptibility. Infect Control Hosp Epidemiol. 2013;34:1070-6.

57. Rubin JE, Ekanayake S, Fernando C. Carbapenemase-producing organisms in food, 2014. Emerg Infect Dis. 2014;20:1264-5.

58. French GL. Enterococci and vancomycin resistance. Clin Infect Dis. 1998;27:75-83.

59. Swaminathan M, Sharma S, Blash SP, et al. Prevalence and risk factors for acquisition of carbapenem-resistant Enterobacteriaceae in the setting of endemicity. Infect Control Hosp Epidemiol. 2013;34:809-17.

60. Thadan JT, Lewis SS, Hazen KC, et al. Rising rates of carbapenem-resistant Enterobacteriaceae in community hospitals. A mixed-methods review of epidemiology and microbiology practices in a network of community hospitals in the South-Eastern United States. Infect Control Hosp Epidemiol. 2014;35:978-83.

61. Jones CL, Clancy M, Honnold C, et al. A fatal outbreak of an emerging clone of extensively drug-resistant Acinetobacter baumannii with enhanced virulence. Clin Infect Dis. 2015;61:145-54. 
62. Promed-mail on 23 Jan 2015. Acinetobacter - Germany: fatal, nosocomial, multidrug-resistance.

63. Jacoby TS, Kuchenbecker RS, dos Santos RP, et al. Impact of hospital-wide infection rate, invasive procedures use and antimicrobial consumption on bacterial resistance inside an intensive care unit. J Hosp Infect. 2010;75:23-7.

64. Andersen BM. Food borne infection is a neglected problem. Viten Aftenposten, 28 Oct 2014.

65. Zhou JJ, Patel SJ, Jia H, et al. Clinicians' knowledge, attitudes, and practices regarding infections with multidrug-resistant Gram-negative bacilli in intensive care units. Infect Control Hosp Epidemiol. 2013;34:1-14.

66. Grub C, Holberg Petersen M, Medbøe S, Andersen BM, et al. A multi-drug resistant, methicillin-susceptible strain of Staphylococcus aureus from a neonatal intensive care unit in Oslo. Scand J Infect Dis. 2010;42:148-51.

67. Banach DB, Francois J, Blash S, et al. Active surveillance for carbapenem resistant Enterobacteriaceae using stool specimens submitted for testing for Clostridium difficile. Infect Control Hosp Epidemiol. 2014;35:82-4.

68. Lee BY, McGlone SM, Doi Y, et al. Economic value of Acinetobacter baumannii screening in the intensive care unit. Clin Microbiol Infect. 2011;17:1691-7.

69. Septimus EJ, Hayden MK, Kleinman K, et al. Does chlorhexidine bathing in adult intensive care units reduce blood culture contamination? A pragmatic cluster-randomized trial. Infect Control Hosp Epidemiol. 2014;35:17-22.

70. NORM/NORM-VET 2013-2016.

71. Balm MND, Salmon S, Jure R, et al. Bad design, bad practices, bad bugs: frustration in controlling an outbreak of Elizabethkingia meningoseptica in intensive care units. J Hosp Infect. 2013;85:134-40.

72. Bracco D, Dubois MJ, Bouali R, Eggimann P. Single rooms may help to prevent nosocomial blood stream infection and cross-transmission of methicillin-resistant Staphylococcus aureus in intensive care units. Intensive Care Med. 2007; https://doi.org/10.1007/s00134-007-0559-5.

73. Teltscher DY, Hanley J, Loo V, et al. Infection acquisition following intensive care unit room privatization. Arch Intern Med. 2011;171:32-8. 